Regards sur l'économie allemande

Bulletin économique du CIRAC

$84 \mid 2007$

Varia

\title{
Hôpital : qualité des soins mais manque de personnel
}

Isabelle Bourgeois

\section{CpenEdition}

Édition électronique

URL : http://journals.openedition.org/rea/578

DOI : 10.4000/rea.578

ISBN : 978-2-8218-0864-5

ISSN : 1965-0787

\section{Éditeur}

CIRAC

Édition imprimée

Date de publication : 1 décembre 2007

Pagination : 38

ISSN : 1156-8992

Référence électronique

Isabelle Bourgeois, " Hôpital : qualité des soins mais manque de personnel », Regards sur l'économie allemande [En ligne], 84 I décembre 2007, document 4, mis en ligne le 01 décembre 2009, consulté le 15 septembre 2020. URL : http://journals.openedition.org/rea/578

Ce document a été généré automatiquement le 15 septembre 2020

(c) CIRAC 


\section{Hôpital : qualité des soins mais manque de personnel}

Isabelle Bourgeois 
1 Le coût des soins stationnaires dans les 2104 hôpitaux que compte l'Allemagne était de 58 milliards $€$ en 2006, soit 2,3\% de plus en un an (Destatis). La hausse (1,3 milliards $€$ ) est due majoritairement aux coûts d'infrastructure et d'équipement $(+5,9 \%)$, la masse salariale n'ayant progressé que de $0,6 \%$. Si le coût moyen des soins par patient s'est élevé à $3447 €(+0,5 \%)$, les disparités régionales sont fortes : la fourchette s'étend entre $2920 €$ (Mecklembourg) et $3919 €$ (Berlin), voire $4009 €$ (Hambourg). Dans ces deux derniers Länder, les coûts sont néanmoins en baisse ( $-0,7 \%$ pour le Land capitale, $-4,1 \%$ pour la métropole portuaire). Les dépenses brutes des hôpitaux, qui incluent notamment les soins ambulatoires, la recherche et l'enseignement, ont atteint 66,1 milliards $€$. La masse salariale s'y taille la part du lion avec $62,3 \%$ des dépenses.

2 Malgré cet intense effort financier et une série de réformes, l'image qu'ont les Allemands des soins hospitaliers reste mitigée : elle est bonne pour $44 \%$ seulement des Allemands et ne s'est pas améliorée depuis 1970 (45\%), comme le révèle une enquête effectuée en octobre 2007 par l'Institut für Demoskopie d'Allensbach pour le prestataire de services financiers MLP auprès d'un échantillon représentatif de 1879 personnes de plus de 16 ans ayant fait récemment un séjour à l'hôpital (MLP-Gesundheitsreport 2007). Si la qualité des médecins et du personnel soignant n'est pas en cause, bien au contraire, puisque $91 \%$ des sondés se disent satisfaits (et que $50 \%$ louent la compétence des médecins), le bât blesse quant à leur disponibilité. $53 \%$ des personnes interrogées estiment que "les médecins n'ont pas assez de temps à consacrer au patient"; ils n'étaient que $31 \%$ à faire le même constat en 1995. Aujourd'hui, 37 \% regrettent la pénurie de personnel soignant (29\% seulement en 1995). Mais $76 \%$ des Allemands soulignent sa prévenance et sa serviabilité. La même proportion relève la grande propreté des locaux, même si $20 \%$ des sondés considèrent que les équipements sanitaires ne sont pas suffisants...Un progrès à constater néanmoins, et qui traduit les récents gains d'efficience du système hospitalier allemand : les sondés ne sont plus que $12 \%$ à penser qu'ils auraient pu quitter l'hôpital plus tôt.

\section{INDEX}

Mots-clés : emploi, hôpital, marché du travail, santé 